\title{
MIMR WASTAGE OF IMAGING MATERIALS IN MEDICAL CONVENTIONAL, SPECIALISED IMAGING AND THE RELATIONSHIP IN CONTINUOUS PROFESSSIONAL DEVELOPMENT
}

\author{
Alfonce Mang'oka M.Nyalla \\ Medical Imaging Sciences Department, Kenya Medical Training College. Kenya \\ Corresponding Author's Email:nyallaa2@yahoo.com.
}

\begin{abstract}
Imaging materials are the most important consumables in X-ray Departments and are key to the cost-effective running of the departments. While in use, some materials like radiographs are spoiled and discarded due to several reasons. At the same time, the skills that the radiographers have in producing radiographs play a major role in whether the film is accepted or rejected. The aim of this study was to undertake a wastage survey of materials used in conventional, specialized medical imaging and their relationship with Continuous Professional Development (CPD).
\end{abstract}

Data collection was done in Mbangathi District Hospital. Phase one involved the collection of radiographs and print paper wasted during examinations that were discarded. Phase two of the study was concerned with the filling in of questionnaires by the radiographers working in Mbagathi hospital regarding CPD. The study applied a descriptive design.

The findings revealed that at Mbagathi X-Ray Department the wastage rate was $5.47 \%$. There were various reasons for radiograph wastage in Mbagathi Hospital which included exposure errors 59\%, positioning $11 \%$, processing $11 \%$ and film fog at $19 \%$. From the results, exposure errors emerged as a major area where most wasted radiographs came from. The results from the questionnaire completed by the radiographers regarding CPD revealed that lack of finances was the most common obstacle to the attendance of continuous professional development activities (90.9 $\%)$, followed by poor communication $(72.7 \%)$, lack of time $(54.5 \%)$ and the infrequent organization of CPD activities $(27.3 \%)$.

Key words: Imaging Materials, Wastage and Continuous Professional Development

\section{INTRODUCTION}

Materials which include X-ray films and print paper are used to record images for diagnostic and treatment purposes in an X-ray department. These images help the clinician to diagnose the disease from which the patient is suffering so that proper treatment can be instituted appropriately. X-ray imaging relies on the attenuation of X-rays through the patient where the transmitted X-ray beam detects and produces a 2dimensional image of the X-ray interactionsthat depict the patient's anatomy (Seibert \& Boone, 2005). During $\mathrm{X}$-ray imaging, materials and paper are utilized to record the patient's anatomical structures. Materials that are of no value in making a diagnosis are rejected due to various reasons. The reasons can be classified as mainly being due to human (radiographers) and technical equipment faults. Materials wasted due to the fault of radiographers are a result of incorrect selection of exposure factors, poor positioning of both the patient and the film holder (cassette), film fog and film processing. Some of the equipment faults are noncompletion of exposure, faulty rollers and nonalignment of the light beam diaphragm (Dunn \& Rogers 1998).

Apart from rejected materials having no diagnostic value, the financial situation of the $\mathrm{X}$-ray department is negatively affected and there is a delay in the treatment of patients. Discarded films require patients to undergo repetitive $\mathrm{X}$-ray examinations thus subjecting them to excess ionizing radiation exposure and avoidable extra costs. Therefore, this creates a situation which necessitates the need to explore causes of wastage of imaging materials and repeated X-ray examinations (Zewdeneh, Teferi \& Admassie, 2008).

All hospitals with medical imaging equipment should be accountable for the films used. A wastage analysis programme provides a frame work to manage film usage, monitor equipment performance and measure the effectiveness and performance of the radiographer 
through quality assurance programmes .Radiographers play a major role in the production of diagnostic X-ray films. On the other hand, continuous training of radiographers through specific professional development programmes is likely to maintain the quality of radiographs produced and hence the ability to reduce wastage. hand, continuous training of radiographers through specific professional development programmes is likely to maintain the quality of radiographs produced and hence the ability to reduce wastage.

CPD is a combination of approaches, ideas and techniques that help radiographers manage their own learning and growth. The focus of CPD is on results and some of the benefits of CPD are building the radiographer's confidence and credibility, achievement of goals and coping positively with change by constantly updating skills and becoming more productive and efficient (Henwood, Yielder \& Flinton, 2004). In Kenya and other parts of the world, CPD is a form of training intended to update skills (psychomotor), knowledge and attitude of radiographers in order to keep abreast of new technologies and be able to provide a better imaging service to patients.

\section{RESEARCH METHODOLOGY}

The study was descriptive in design. In phase one, wasted films and print paper were collected and categorized according to the reasons for wastage, namely human and technical errors.Different designs of research have different advantages and disadvantages. The purpose of the design is to achieve greater control of the study and improve the validity of the study. It gives direction and synthesizes the research as asserted by Trochim, 2006.. The method chosen will affect the results and the conclusions drawn from the findings. Most scientists are interested in getting reliable observations that can help the investigation of a phenomenon (Burns \& Grove, 2005). Therefore the design chosen was considered appropriate for this study. Computer package SSP 13 was used for data analysis.

\section{Study Population}

The study population for phase one consisted of 5,550. The 5,550 films included films used to make a diagnosis and films which were of no diagnostic value, referred to as wasted films. Phase two of the study consisted of eleven radiographers working at MDH. The radiographers completed the questionnaires and returned them to the researcher at different times. These questionnaires were designed and administered by the researcher.

\section{Study Sample}

All the wasted or discarded films during the data collection period formed the sample size of the project using convenience sampling method. These films were collected at a strategic point by placing them in a labelled container.

\section{RESULTSAND DISCUSSSION}

Rejected films as alluded to have no diagnostic value and affect the economy of the department, delay treatment and management of the patient and further increase radiation dosage to the patient (Dunn \& Rogers, 1998). A monthly or quarterly audit of rejected films helps a department to identify reasons and solutions for film and print paper rejection hence saving the department a great deal of finances (Lloyd, 2001). CPD activities on image quality and ways of reducing film rejection are essential for radiographers but there are many challenges.In addition, majority of radiographers do not attend CPD programs, Reasons for this could be that the existing diploma requires updates to meet the requirements of rapidly changing technology. They claim that the time given is not adequate, finances are scarce, and time is also a challenge. Financial challenges were listed by $72.7 \%$ of the radiographers as one of the major obstacles pertaining to the attendance of CPD activities. Table 4.1

Tables and Figures used in the Article

Table 4. 1: CPD participation challenges

\begin{tabular}{|c|c|c|}
\hline Challenge & Frequency & Percentage \\
\hline Finance & 8 & 72.7 \\
\hline No classes given & 1 & 9.1 \\
\hline No response & 2 & 18.2 \\
\hline Total & 11 & 100 \\
\hline
\end{tabular}

Seventy two percent of the radiographers (Table 4.1) revealed that finances were a hindrance to CPD participation. 
Figure 4.1 below is presented to further illustrate the film rejection

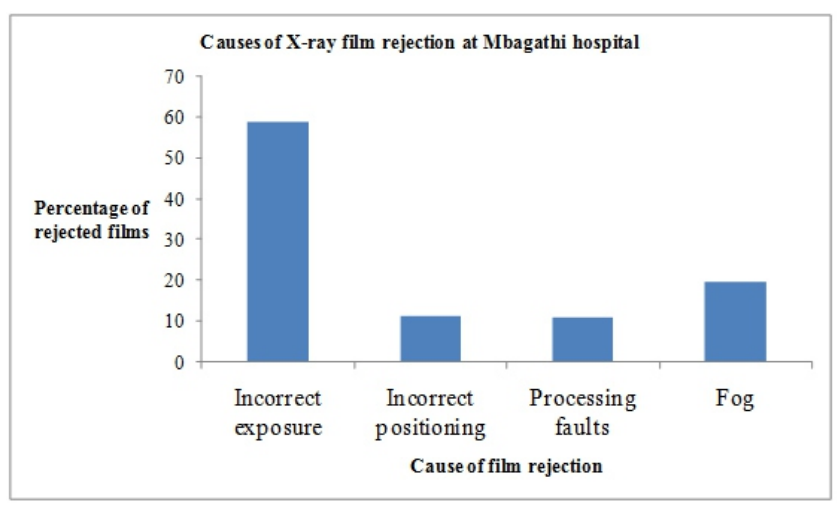

Figure 4. 1: Causes of film rejection

Table 4.2: CPD participation challenges

\begin{tabular}{|c|c|c|}
\hline CPD participation challenge & Frequency & Percentage \\
\hline No communication given & 1 & 9.1 \\
\hline Poor communication & 3 & 27.3 \\
\hline Time & 6 & 54.5 \\
\hline Missing-No response & 1 & 9.1 \\
\hline Total & 11 & 100 \\
\hline
\end{tabular}

In Table 4.2, the majority (54.5\%) of the respondents revealed that time posed a challenge in the participation of CPD programs.

$4.90 \%$. Another study by (Weatherburn, Bryan \& West 1999) it was found that the total film reject rate in the UK stood at 10\%. (Sheung-Ling Lau et al., 2004) in a study done in China, they found that the total film reject rate was $3.4 \%$. In MDH the total film reject rate was $5.47 \%$. The following are areas to be addressed to reduce film rejection rates.

\section{Second Objective: Causes of Film Rejection}

The reasons for film rejection observed at the MDH were as follows:

- Incorrect Exposure factors at 59\%;

- Incorrect patient positioning at $11 \%$;

- Processing faults at $11 \%$;

- Film fog at $19 \%$.

\section{Incorrect Exposure Factors}

The results of the study demonstrated that the major cause of film rejection was incorrect exposure factors which contributed $59 \%$ of the total film wastage. The findings compare with those recorded by (Sheung-Ling Lau et al., 2004), in a study done in China which showed that $38.6 \%$ of the causes of film rejection were due to incorrect exposure factors. Exposure factors are set by radiographers, and if done correctly, it will translate into good practice and high image quality. However, (Claude et al.,1999) found that film rejection rate was highest due to human error. To rectify the situation, exposure charts are utilized in most X-ray departments and more so in MDH as asserted by the radiographers.

\section{Incorrect Patient positioning}

Incorrect patient positioning was the second highest cause of film rejection in this study at $\mathrm{MDH}$ which stood at $11 \%$. In a study by (Sheung-Ling Lau et al., 2004) incorrect patient positioning contributed to $28.2 \%$ of radiographers' errors. Good radiographic technique is therefore paramount in order to avoid repeat exposures leading to film rejection. Apart from incorrect patient positioning, there are many body regions which are very difficult to position as identified in a study done by (Nixon et al.,1995). These regions pose a challenge to the radiographer. Good radiographic technique is therefore paramount in order to avoid repeat exposures hence wastage.

\section{Processing faults}

The other cause of film rejection identified in this study was processing faults at $11 \%$. This is caused by faulty processing equipment, lack of maintenance and cleaning. Bimonthly and monthly checks of the film processors can be done as well as the cleaning of rollers. QA programs ensure good performance of the film processors hence quality films and minimal film rejection due to processing faults (Waailer \& Hofmann, 2010).Felt that mother had the final say regarding the decision to, and stop breast feeding, a number of fathers were still involved in decisions about whether and how long to breast feed.A recent study has shown that Jordan all fathers considered breastfeeding as the mothers' responsibility, the mothers had the final say regarding the decision to breastfeed and they had no The other cause of film rejection identified in this study was processing faults at $11 \%$. This is caused by faulty processing equipment, lack of maintenance and cleaning.Bimonthly and monthly checks of the film 
Lack of finances at $72.7 \%$ was the highest. Funding has always been a challenge especially in the developing countries. Finance is a big challenge for radiographers especially in the developing countries as they may not have sufficient funds to sponsor themselves for CPD activities and the institutions for which they work may also lack these finances as observed by (Henwood \& Huggett,1993). This is the same situation at $\mathrm{MDH}$.

- Lack of time at $54.5 \%$. Lack of time emerged to be the second highest challenge in CPD activities attendance.

- Poor communication at $27.3 \%$. Incorrect communication or delay may influence nonattendance of CPD activities by radiographers.

These findings are in agreement with most other author such as Claude et al., 1999, who found that there is limited research in the field of CPD activities and their effect on health behavior and film rejection rate. Although CPD is a new concept in the minds of radiographers in the developing countries, such as Kenya, the Kenyan government is embracing this concept and recognizes that the provision of funds is quite crucial. The Kenya government is being assisted by professional bodies like the:

-Nursing Council of Kenya;

- Society of Radiographers Kenya;

- Pharmacy Drugs and Poisons Board;

- Clinical Medicine Board;

- Medical Laboratory Technology and Technician Board.

The researcher supports the existence of these boards which are key to the maintenance of standards, training needs, quality and the implementation of CPD in Kenya. The fact remains that if countries hide behind finances or funding, there might be lack of achievement in this regard hence the need for self sacrifice and commitment on the part of radiographers.

The study findings have revealed that the rejection rate at the MDH is within recommendations for maximum acceptable rejection rates. However, despite the rejection rate at the $\mathrm{MDH}$ being within the recommended acceptable maximum limits, of the rejected films, $59 \%$ was due to incorrect exposure factors. This is something which the department needs to pay attention to. In most departments, a standard chart for exposure factors is made available as a reference. However, the researcher did not establish the existence of such charts at MDH. The rejection rate may be influenced by the small number of radiographers who attend CPD activities in general Identification of CPD for radiographers at the MDH through the questionnaire as well as film rejection analysis by the study showed that CPD activities relevant to the needs of the radiographers can be formulated. This is in agreement with (Friendman \& Phillips, 2001) who mention that organizations are willing to fund their employees' CPD activities, but such activities should be justified in terms of specific relevance.

\section{CONCLUSIONS}

\section{Study implications}

The implications of the findings in this study are important to the Department of Radiography at the MDH and should be owned by both the radiographers, management of the department and as well as the hospital management.

From the questionnaire, the following CPD challenges emerged:

- Lack of time;

- Lack of finance;

- Infrequent organization of CPD activities;

- Poor communication;

- Non-relevancy of the professional development activities meaning that the activities carried out were not addressing the key issues related to film rejection,namely, correct selection of exposure factors and correct patient positioning.

Seventy two percent of the radiographers (Table 4.10) revealed that finances were a hindrance to CPD participation and $82 \%$ (Figure 4.2 ) felt they needed training in patient positioning and correct selection of 
exposure factors as a priority and not more generalized programs.

\section{ACKNOWLEDGEMENT}

The author is highly grateful to Dr. Amiya Bhaumik, Dr. Sandeep Poddar and Dr. Arindam Das for their dedicated guidance, resilience, patience, advice and assistance in the organization, preparation and carrying out of the thesis and journal article.

The author is also very thankful to Mr. John Kandie Kurui, Senior Principal Lecturer and Head of the Department of Health Records and Information, Kenya Medical Training College, Mr. Mark Mudenyo, Chief Health Records and Information Officer, Kenyatta National Teaching and referral Hospital, for statistical support, Dr. Joash Auka, Consultant Radiologist and Senior Lecturer and Luke Kanamu, Principal Lecturer, Medical Imaging Department.

The author is thankful to Beatrice Auka for his statistical analysis. The author is also grateful to the Mbagathi District Hospital, Aga Khan University Hospital, Radiographers and 3rd year Medical Imaging Sciences students 2006 for their wonderful support under the supervision of Patrick Mitei and and Mr Lincoln Njiru.

\section{REFERENCES}

Burns, N. \& Grove, S. K. (2005). The practice of nursing research, Elsevier, Missouri, USA.

Lloyd,P.J.2001Quality assurance workbook for radiographers and radioogical technologists, WHO, Geneva.

Dunn, M.A. \& Rogers, A. T. (1998).X-ray film analysis as a quality indicator. Radiography, 4(1), pp 29-31.

French H. P \& Dowds. J. (1999). An overview of continuing professional development in physiotherapy, 94(3), pp 190-197

Friendman,P. (2001).Continuing Professional Development, Leeds, UK

Henwood, S. M., Yielder, J. \& Flinton, D. (2004).
Radiographers attitude to mandatory CPD: A comparative study In the United Kingdom and New Zealand, Radiography, 10(4), pp 251-258.

Hoeffel, J. \& Hoeffel, C. (1999). X-ray film rejects analysis as a quality indicator. Radiography, 5(2), page 117.

Lloyd,P. J.2001Quality assurance workbook for radiographers and radioogical technologists, WHO, Geneva.

Naqvi, S.A., Rizvi, S.A., Zafar, M.N., Ahmed, E., Ali, B., Mehmood, K., Awan, M.J., Mubarak, B.\& Mazhar, F.(2008). Health status and renal function evaluation of kidney vendors: a report from Pakistan. American Journal of Transplantation. 8, pp 1444-1450.

Nixon, P. P., Thorogood, J., Holloway, J. \& Smith, N. J. D. (1995). An audit of film rejects and repeats rates in a department of dental radiology. The British Journal of radiology, 68(816), pp 1304-1307.

Sheung-Ling L., Anna, S. M., Wing-tat L., Chi-kwok C, \& Ka-yin L.(2004). Reject analysis. A comparison of conventional film-screen radiography and computed radiography with PACS. Radiography, 10(3), pp 183-187.

Seibert, J. A. \& Boone, J. M. (2005). X-ray imaging physics for nuclear medicine technologists, Lippincott, Baltimore, America

Waailer, D. \& Hofmann, B. (2010). Image rejects/retakes-Radiographic challenges. Radiation Protection Dosimetry, 139(1-3), pp 375-379.

Weatherburn, G. C., Bryan, S. \& West, M. (1999). A comparison of image reject rates when using film, hard copy computed radiography and soft copy images on picture archiving and communication systems (PACS) workstations. The British Journal of Radiology, 72(859), pp 653-660.

Zewdeneh, D., Teferi, S. \& Admassie, D. (2008). X-ray reject analysis in Tikur, Anbessa and Bethzatha Hospitals. Ethiopian. Journal of Health Development. 22(1), pp 63-67. 